\title{
Cross-category demand effects of price promotions
}

\author{
Peter S. H. Leeflang • Josefa Parreño-Selva
}

Received: 5 February 2010 / Accepted: 14 December 2010 / Published online: 12 February 2011

(C) The Author(s) 2011. This article is published with open access at Springerlink.com

\begin{abstract}
Do promotions in a certain category lead to higher revenues in other categories? If so, to what degree? The answers to these questions are highly relevant for retailers that supply products in different categories. Empirical findings in studies that consider a limited number of categories indicate small promotional cross-category effects. This study develops a framework to determine the impact of price promotions on category revenues that include interdependencies among a substantial number of categories at the category demand level. The own- and cross-category demand effects are moderated by variables such as promotion intensity, category characteristics (own-category effects), and spatial distances between shelf locations (cross-category effects). The empirical results based on daily store-level scanner data show that approximately half of all price promotions expand own-category revenues, especially for categories with deeper supported discounts. There is a high probability (61\%) that a price promotion affects sales of at least one other category. The number of categories affected is not greater than two. Moderate evidence supports the existence of cross-promotional effects between categories more closely located in a store.
\end{abstract}

P. S. H. Leeflang $(\bowtie)$

Department of Marketing, Faculty of Economics and Business, University of Groningen,

P.O. Box 800, NL-9700 AV Groningen, The Netherlands

e-mail: p.s.h.leeflang@rug.nl

P. S. H. Leeflang

Faculty of Economics and Business, Luiss Guido Carli, Rome, Italy

\section{J. Parreño-Selva}

Department of Marketing, Faculty of Economics,

University of Alicante,

P.O. Box 99, 03080 Alicante, Spain

e-mail: pepi@ua.es
Keywords Cross-category effects · Category demand model $\cdot$ Price promotions $\cdot$ Store-level scanner data $\cdot$ Daily data

\section{Introduction}

Price promotions often result in large sales effects for a promoted item, but this influence does not necessarily mean that the sales increase is truly beneficial for retailers and/or manufacturers (Ailawadi et al. 2006, 2007; Srinivasan et al. 2004). A retailer does not benefit from brand switching within the store, unless it exploits margin differences. However, a store could benefit from the impact of price promotions on store switching or from the impact of price promotions on category demand in the focal and other categories (crosscategory or cross-promotion effects) (Walters 1991).

Although the impact of promotions can be measured at the item (SKU), brand and category level, the category level is the most relevant level for retailers (Ailawadi et al. 2009). Compared with the vast volume of studies pertaining to the effects of price promotions on brand choice and brand sales, research on category-demand effects in a retail store remains sparse.

Most empirical studies based on either household data (Song and Chintagunta 2007) or store-level data (Leeflang et al. 2008) demonstrate small cross-category effects. These studies consider cross-category effects between a small number or pairs of categories and analyze categories that appear complementary. Existing literature also reveals demand interdependencies between unrelated categories, including those that are not a priori perceived as complements or substitutes (Campo et al. 2000; Seetharaman et al. 2005). The managerial relevance of outcomes of studies that only consider complementary categories is thus rather low. 
In this study, we develop a multicategory model that considers demand interdependencies (substitution and complementarities) at the product category level. The first aim of this study is to analyze the impact of promotion intensity in one category on the attraction of this focal and other (related and unrelated) categories, using a substantial number of product categories. We analyze two category clusters, aperitifs and breakfast products, which consist of 12 and 13 product categories respectively, and use daily data that refer to a Spanish supermarket. Unlike other studies that are based on store-level data, we consider crosspromotion effects of related and less related/unrelated product categories. Hence the second aim of the study is to determine cross-promotional effects between these product categories.

The third aim of this study is to determine which factors might moderate these own - and cross-elasticities. Extant research identifies different moderators that determine the size of (short-run) own price promotion elasticities (see Grewal and Levy 2007; Nijs et al. 2001). Factors such as promotion frequency and promotion depth are tools managers might use to influence demand sensitivity, at least in principle. Some studies suggest that the location of a promoted category also can influence the sales of other categories, even if they are not complements or substitutes (Campo et al. 2000; Heilman et al. 2002). In this study, we also determine whether the distance between categories and other predictors might help explain cross-category elasticities.

To study the cross-category effects of price promotions at the retail store level, we first develop our conceptual framework, which includes moderators such as location factors, intensity of promotional activity, and category characteristics. Then, we discuss our data, propose our model, and present the results. We conclude with managerial implications and further research directions.

\section{Conceptual framework}

We review studies on cross-category promotion effects based on store-level data. In one of the first studies, Walters and MacKenzie (1988) analyze the impact of price promotions (loss leaders, double coupon promotions and in-store price specials) on store traffic, sales of promoted and unpromoted products, and store performance using a structural equation approach and store-level data. They do not find any evidence that sales of promoted items stimulate sales of unpromoted items. Mulhern and Leone (1991) also use weekly store-level scanner data to estimate promotion effects between complementary categories (e.g., cake mix and frosting) and, similar to other studies, suggest that promotions in one category enhance sales in the other. Also using related categories, Walters (1991) addresses two predefined sets (cake mix and frosting; spaghetti and spaghetti sauce) and two stores. His findings reveal significant intrastore complementarity and substitution effects but little evidence of interstore effects.

To achieve a better understanding of brand competition across three subcategories of orange juice, Wedel and Zhang (2004) develop a model that represents cross-(sub) category price effects specific to individual brands or SKUs. They find that the between-subcategory crosseffects are smaller than the within-subcategory crosseffects.

Song and Chintagunta (2006) derive econometric specifications of response models on the basis of utility maximizing behavior at the household level. With storelevel aggregate scanner data for four product categories, they find some evidence for cross-category price effects, mostly driven by complementary relationships (i.e., liquid softeners and liquid/powered laundry detergents).

Ailawadi et al. $(2006,2007)$ quantify the net unit and net profit impact of promotions for a (drug) retailer by determining the gross promotional lift, which consists of (1) sales switched from other stores and other brands in the same period, (2) sales switched from other brands/stores in future periods, and (3) increases in category consumption. They explicitly estimate a halo effect, or the extent to which promotions affect sales of other categories in the store. They find a positive halo effect: For every unit of gross lift, 0.16 units of some other product gets purchased elsewhere in the store. They specify cross-category effects only at the aggregate level. Effects are aggregated over related and unrelated categories.

Kamakura and Kang (2007) investigate cross-category price promotion effects among 66 stores and two related categories (toothpaste and toothbrushes). They determine a limited number of significant, asymmetric, intrastore complementary and substitution effects.

Finally, Leeflang et al. (2008) modify Van Heerde et al.'s (2004) model to allow price changes on an item in one category to affect the purchase of items in other categories. Because of the difficulties of accommodating crosscategory effects for many categories simultaneously, they consider only pairs of related categories, but their model permits both positive (complementary) and negative (substitution) cross-category effects. Their findings reveal that complementary between-category effects are approximately $20 \%$ of the own-brand effect on revenues; betweencategory substitution effects are roughly $9 \%$. We summarize these studies in Table 1.

As these summaries of the studies and outcomes show, most research considers only a limited number of related categories, the number and size of the cross-category effects are small, and most effects are found between related categories. 
Table 1 Overview of studies of cross-category promotion effects, store-level data

\begin{tabular}{|c|c|c|c|c|c|c|}
\hline \multirow[t]{2}{*}{ Study } & \multicolumn{3}{|c|}{ Categories } & \multicolumn{2}{|c|}{ (Intrastore) Effects } & \multirow[t]{2}{*}{ Aggregation Level } \\
\hline & Number & Related & Unrelated & Complementary & Substitution & \\
\hline Walters and MacKenzie (1988) & $2^{\mathrm{a}}$ & - & - & No & No & Category \\
\hline Mulhern and Leone (1991) & 2 & $\sqrt{ }$ & - & Yes & Yes & Brand \\
\hline Walters (1991) & 2 & $\sqrt{ }$ & - & Yes & Yes & Brand \\
\hline Wedel and Zhang (2004) & $3^{\mathrm{b}}$ & $\sqrt{ }$ & - & Yes & Yes (but small) & SKU's/Brands \\
\hline Song and Chintagunta (2006) & 4 & $\sqrt{ }$ & - & Yes & Yes & Brand \\
\hline Ailawadi et al. $(2006,2007)$ & $2^{\mathrm{a}}$ & $\sqrt{ }$ & $\sqrt{ }$ & Yes & Yes & Category \\
\hline Kamakura and Kang (2007) & 2 & $\sqrt{ }$ & - & Yes & Yes & Brand \\
\hline Leeflang et al. (2008) & 2 (pairs of categories) & $\sqrt{ }$ & - & Yes & Yes & SKU's/Categories \\
\hline This study & 12 and 13 & $\sqrt{ }$ & $\sqrt{ }$ & Yes & Yes & Category \\
\hline
\end{tabular}

${ }^{a}$ Promoted versus non-promoted items

${ }^{\mathrm{b}}$ Subcategories

Promotional effects

There is another set of studies that considers moderating variables that may influence promotional effectiveness. We will discuss these after we formulate our expectations about promotional and cross-promotional effects on revenues.

Considering the limited cross-category promotional effects in previous studies, we expect that:

P1a: The promotional effects of items/brands in category $i$ primarily affect revenues in category $i$.

P1b: The cross-promotional effects on revenues are limited, i.e., promotional effects of items/brands in category $(i)$ influence the revenues of only a limited number of other categories, $j, j, i=1, \ldots, n, j \neq i$.

Furthermore, empirical findings of promotional effects at the item/brand level (Wittink et al. 1988) and category level (Bezawada et al. 2009; Song and Chintagunta 2007) indicate that own elasticities are greater in absolute value than cross elasticities. Therefore, we expect:

P2: Significant own-category elasticities are greater than significant cross-category elasticities (in absolute values).

Price promotions supported by a display or featured at the SKU/brand level (or both) have substantially greater effects than unsupported price promotions (Van Heerde et al. 2001, 2004). We investigate whether this finding holds at the category revenue level and expect that:

P3: The effect of a price promotion (a) within and (b) between categories depends on support for the promotion. Supported price promotions have greater effects on category revenues than unsupported price promotions.
Figure 1 represents the relations between supported and unsupported price promotions within and between categories.

We observe in Fig. 1 that the revenues of the categories 1 and $n$ are affected by supported and unsupported price promotions in all categories $i=1, \ldots, n$, at least in principle. This also holds for the categories 2, $\ldots, n-1$. In Fig. 1 we also indicate links between the ownand cross-price promotion elasticities and the promotion efforts. The parameters $\beta$ and $\delta$ refer to Eq. 1 that will be introduced later. Figure 1 also depicts several moderators that may influence promotional effectiveness: promotional intensity, competition intensity within the category, and location factors. First we discuss moderators that may affect the own elasticities (see the left-hand top box of Fig. 1).

\section{Own elasticities}

Promotional intensity We consider two components of promotional intensity that may affect the estimated values of own-price elasticities: price promotion frequency and price promotion depth (see Nijs et al. 2001, 2007; Raju 1992).

Studies demonstrate the effect of frequency on price promotion elasticities at both brand and category levels, but no consensus indicates the direction of the effect. Adaptation-level theory (Helson 1964), the associated concept of reference price, and consumer stockpiling behavior theory predict that price promotion frequency leads to lower elasticities (e.g., Foekens et al. 1999), because if promotional frequency increases, the probability of stockpiling decreases (Helsen and Schmittlein 1992). A higher price promotion frequency also can increase price promotion effectiveness in the short run. Consumers learn 


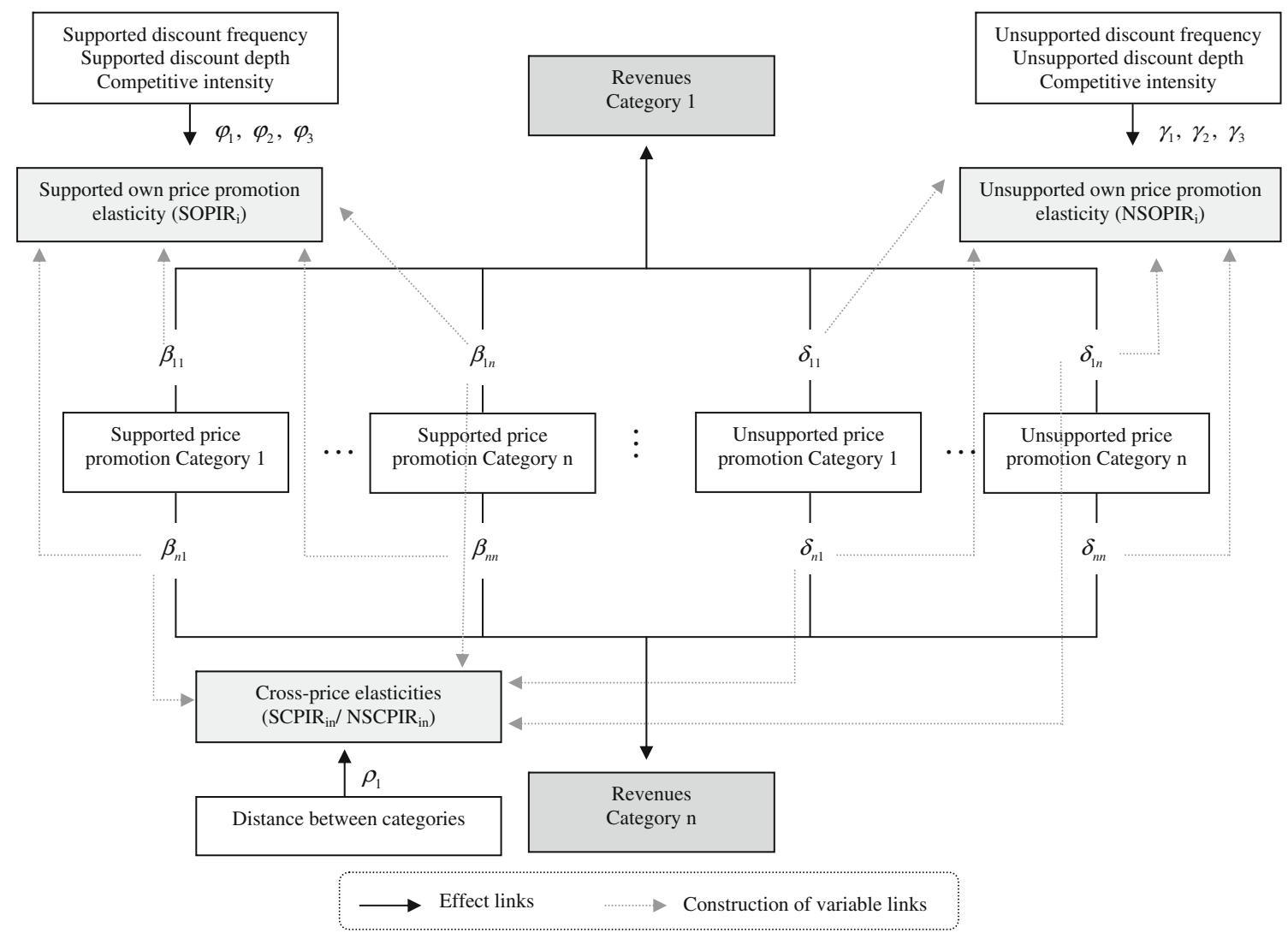

Fig. 1 Conceptual framework

to buy only during price promotions (Krishna et al. 1991; Mela et al. 1997). Nijs et al. (2001) support this positive effect in the short run but find that it disappears in the long run. Kumar and Pereira (1995) further show that both positive and negative effects of frequency are possible, depending on the schedule of promotions. Hence we are not able to specify expectations.

Price promotion depth measures the average size of the magnitude of discounts. Deep price cuts should result in more additional purchases and consumer stockpiling than lower price reductions, because deep price cuts induce non-loyal consumers to switch categories and loyal consumers to engage in heavier stockpiling and consumption (Ailawadi et al. 2006; Raju 1992; Walters and Bommer 1996). However, Nijs et al. (2001) find no significant effects of price promotion depth on price promotion elasticity, in either the short or the long run. Therefore, we again have no specific expectations.

Category characteristics The competition intensity within a category depends on the number of brands within it. When a category consists of more brands, brand switching effects dominate (Narasimhan et al. 1996; Raju 1992). The cost of consumer search also increases with the number of brands to be evaluated (e.g., Ratchford 1980). These arguments are consistent with the empirical short-run effects found at the category level (Ailawadi et al. 2006; Narasimhan et al. 1996; Raju 1992), though Nijs et al. (2001) indicate they disappear in the long run. We therefore expect:

P4: The number of brands in a category has a negative impact on own-category promotion elasticities.

Cross elasticities

Location factors Many studies suggest that the locations of product categories in the store affect the estimated values of cross-promotion category elasticities. Campo et al. (2000) demonstrate significant, asymmetric, surface share interdependencies among categories, some positive and others negative. These authors, as well as Heilman et al. (2002), reveal that the location of a category can influence the sales of other categories, even if they are not complements or substitutes. Based on these studies we expect that:

P5: Cross-category promotion elasticities are larger (in absolute value) if the distance between categories is smaller. 


\section{Data}

We use store-level data for 12 and 13 product categories in the clusters of aperitifs and breakfast products, respectively, sold in a Spanish hypermarket. One cluster consists of categories related to aperitifs for lunch or dinner time, whereas the other comprises categories related to breakfast or coffee time. The clusters are based on observed customer behavior (household baskets; see Parreño-Selva et al. 2009) and discussions with a store manager of the Spanish hypermarket. We analyze these clusters because (1) they consist of a substantial number of categories, (2) they are complements, substitutes, or unrelated, (3) they are located close together or farther apart in the store, (4) they are categories in which there are many price promotions, and (5) there are few other categories in the cluster that we do not consider. Within each cluster, products use incomparable units (e.g., kilograms, cans), so we transform sales into revenues using the average price over the whole observation period. This dependent variable has the desirable property of varying only in terms of unit sales (see Appendix 1). The selected product categories also achieve high store shares, and the items within those categories are heavily promoted. For each category, we select the top items for our analysis, generally around $80 \%$ of category revenues.

We have access to 1 year of item-level daily data (301 days) of unit sales, actual prices, and features of the items in each category. The category sales are always positive for each day. Data for displays and regular prices are not available. Therefore, we consider the maximum price during the year as the regular price and calculate price indices relative to that maximum price. That is, we measure larger price "discounts" than those perceived by consumers and engage in a (moderate) underestimation of promotion effects. Almost without exception (in 99\% of the cases), if an item is featured, it also is discounted, so we do not address a feature without price promotion, because these data lack sufficient variability. We use only featuresupported price and non-feature-supported price promotional variables in our analysis. In Table 2, we list the total annual turnover, number of top items, average daily prices with corresponding standard deviations (measure of price fluctuations), and promotional activities for each category. Product dominance varies widely in these categories; for sugar for example, one item enjoys a more than $80 \%$ share, whereas in the cereal category, 23 different items all battle for an $81 \%$ market share.

The categories from the aperitif cluster generally reveal more price promotional activity than those of the breakfast cluster. In the aperitif cluster, the average frequency of supported and unsupported price promotions that exceed $5 \%$ (i.e., actual price is $5 \%$ or more below the maximum price) is $13 \%$ (39 of 301 days) and 36\% (109 of 301 days), respectively. For the breakfast categories, these averages are $6 \%$ (19 of 301 days) and $29 \%$ (87 of 301 days), respectively. Furthermore, the aperitif categories offer an average daily supported price promotion of $11 \%$ and an average daily unsupported price promotion of $9 \%$, whereas in the breakfast categories, the supported and unsupported price promotions are both approximately $5 \%$. The length of these promotions varies between 1 day and 1 week.

The focal hypermarket is located in an area where most of the population earns weekly salaries and lives in relatively small houses that offer little space for stockpiling. We confirmed these characteristics with analyses of empirical models that account for stockpiling effects at the item level. ${ }^{1}$ The hypermarket's only competitor adopts an everyday low price format.

According to our distance measures, the spaces between the categories of different clusters are substantial. The distances between product categories of the aperitif cluster are greater than those of the breakfast cluster $(31$ and $17 \mathrm{~m}$, respectively). Furthermore, product categories contained within the breakfast cluster are all on the first floor of the store, whereas in the aperitif cluster, potato chips and olives are located on the first floor, but the other categories appear on the ground floor.

\section{Model specification}

We perform two analyses. We initially develop a category attraction model to estimate the interdependencies among demand categories in a store. In a second (-stage) analysis, we estimate the effects of moderators on estimated ownand cross-category promotion elasticities.

\section{Category attraction model}

Previous literature addresses asymmetries in the interactions of cross-category effects at the household level (Song and Chintagunta 2007) or store level (Wedel and Zhang 2004), so our proposed model accounts for these asymmetries. Asymmetries can be accommodated using hierarchical and non-hierarchical models (see, for example, Leeflang et al. 2000, p. 287).

For our purpose we consider three different types of nonhierarchical models:

- The Cluster Asymmetry Attraction model (CAA model).

- The Fully Extended Attraction model (FEA model).

- The attraction model developed by Carpenter et al. (1988) (the CCHM model).

\footnotetext{
${ }^{1}$ These analyses are available on request.
} 
Table 2 Descriptive statistics, category level

\begin{tabular}{|c|c|c|c|c|c|c|c|c|c|}
\hline & \multirow{2}{*}{$\begin{array}{c}\text { Total annual } \\
\text { turnover* }\end{array}$} & \multirow{2}{*}{$\begin{array}{c}\text { Number of } \\
\text { top items }\end{array}$} & \multirow{2}{*}{$\begin{array}{c}\text { Average } \\
\text { daily } \\
\text { price** }\end{array}$} & \multicolumn{3}{|c|}{ Supported Price Promotions } & \multicolumn{3}{|c|}{ Unsupported Price Promotions } \\
\hline & & & & $\begin{array}{l}\text { Number } \\
\text { of days }\end{array}$ & $\begin{array}{c}\text { Number of days } \\
\text { discount exceeds } 5 \%\end{array}$ & $\begin{array}{l}\text { Average daily } \\
\text { discount }(\%)\end{array}$ & $\begin{array}{l}\text { Number } \\
\text { of days }\end{array}$ & $\begin{array}{c}\text { Number of days } \\
\text { discount exceeds } 5 \%\end{array}$ & $\begin{array}{l}\text { Average daily } \\
\text { discount (\%) }\end{array}$ \\
\hline \multicolumn{10}{|c|}{ Aperitif product categories } \\
\hline Bottle of beer, 11 & 51.78 & 5 & $0.66(4.95)$ & 36 & 35 & 4.36 & 75 & 47 & 5.48 \\
\hline Can of beer, $33 \mathrm{cl}$ & 146.52 & 4 & $0.28(2.88)$ & 67 & 62 & 10.66 & 82 & 72 & 6.58 \\
\hline Can of mussels & 23.34 & 9 & $1.06(16.47)$ & 89 & 89 & 24.16 & 160 & 130 & 14.62 \\
\hline Can of cockles & 75.48 & 20 & $1.94(29.88)$ & 30 & 28 & 15.18 & 147 & 119 & 5.25 \\
\hline Can of clams & 13.86 & 4 & $1.14(34.37)$ & 71 & 71 & 16.64 & 164 & 126 & 10.21 \\
\hline Can of tuna in oil & 16.68 & 6 & $1.01(9.54)$ & 89 & 77 & 8.84 & 156 & 123 & 8.72 \\
\hline Can of asparagus & 22.98 & 11 & $1.40(18.20)$ & 18 & 18 & 17.54 & 133 & 90 & 10.45 \\
\hline Bottle of red wine & 18.06 & 12 & $1.57(19.19)$ & 16 & 14 & 5.21 & 176 & 125 & 9.41 \\
\hline $\begin{array}{l}\text { Bottle of white/ } \\
\text { rose wine }\end{array}$ & 68.52 & 16 & $2.15(17.11)$ & 17 & 16 & 7.25 & 144 & 93 & 7.73 \\
\hline $\begin{array}{l}\text { Bag of potato } \\
\text { chips }\end{array}$ & 68.88 & 13 & $0.88(15.09)$ & 13 & 13 & 4.99 & 201 & 201 & 18.63 \\
\hline $\begin{array}{l}\text { Can of stuffed } \\
\text { olives }\end{array}$ & 42.36 & 8 & $0.64(8.10)$ & 33 & 33 & 16.22 & 209 & 164 & 9.59 \\
\hline Can of razorshells & 12.66 & 6 & $1.98(22.10)$ & 11 & 11 & 1.54 & 32 & 21 & 3.14 \\
\hline \multicolumn{10}{|c|}{ Breakfast product categories } \\
\hline Juice mini brick & 68.28 & 15 & $1.03(1.22)$ & 35 & 35 & 13.19 & 207 & 135 & 5.12 \\
\hline $\begin{array}{l}\text { Bottle of juice, } \\
11\end{array}$ & 66.36 & 22 & $0.61(0.77)$ & 47 & 47 & 5.99 & 398 & 343 & 15.67 \\
\hline $\begin{array}{l}\text { Pack of standard } \\
\text { cookies }\end{array}$ & 44.76 & 10 & $1.09(2.31)$ & 28 & 25 & 9.91 & 192 & 95 & 6.55 \\
\hline $\begin{array}{l}\text { Pack of filled } \\
\text { cookies }\end{array}$ & 35.34 & 9 & $0.60(1.62)$ & 20 & 19 & 8.91 & 187 & 76 & 4.59 \\
\hline $\begin{array}{l}\text { Pack of soluble } \\
\text { cocoa }\end{array}$ & 63.00 & 6 & $3.54(3.11)$ & 19 & 13 & 7.28 & 206 & 84 & 4.69 \\
\hline $\begin{array}{l}\text { Pack of soluble } \\
\text { coffee }\end{array}$ & 90.54 & 6 & $2.53(0.71)$ & 45 & 0 & 2.15 & 179 & 2 & 1.87 \\
\hline $\begin{array}{l}\text { Pack of normal } \\
\text { coffee }\end{array}$ & 55.80 & 13 & $1.14(2.55)$ & 64 & 60 & 9.75 & 203 & 170 & 7.78 \\
\hline $\begin{array}{l}\text { Brick of } \\
\text { unskimmed milk } \\
11\end{array}$ & 174.66 & 13 & $0.61(0.85)$ & 29 & 29 & 3.90 & 113 & 41 & 1.70 \\
\hline $\begin{array}{l}\text { Brick of skimmed } \\
\text { milk, } 11\end{array}$ & 47.22 & 6 & $0.58(0.53)$ & 15 & 13 & 2.76 & 81 & 29 & 1.25 \\
\hline $\begin{array}{l}\text { Brick of semi- } \\
\text { skimmed milk, } \\
11\end{array}$ & 74.28 & 7 & $0.59(0.58)$ & 5 & 2 & 0.90 & 108 & 5 & 2.10 \\
\hline $\begin{array}{l}\text { Brick of enriched } \\
\text { milk, } 11\end{array}$ & 115.20 & 14 & $0.74(10.83)$ & 2 & 2 & 0.56 & 25 & 15 & 1.33 \\
\hline Pack of cereal & 55.56 & 23 & $1.57(14.13)$ & 6 & 6 & 2.44 & 204 & 131 & 6.58 \\
\hline $\begin{array}{l}\text { Pack of normal } \\
\text { sugar, } 1 \mathrm{~kg}\end{array}$ & 42.00 & 1 & $0.93(0.00)$ & 0 & 0 & 0.00 & 2 & 2 & 0.00 \\
\hline
\end{tabular}

*Turnover is measured in thousands of Euros. **Standard deviations are in parentheses.

In the CAA model (Vanden Abeele et al. 1990) it is assumed that the market can be structured as cluster of items (in our case: categories). Criteria are specified a priori, such that the use of each criterion results in the identification of one or more clusters. If clustering is effective, competition within clusters is stronger than between items of different clusters. The approach allows clusters to be overlapping, i.e., items may belong to more than one cluster. The CAA model incorporates cross-effects which are related to a priori defined clusters of items by introducing one asymmetry parameter per clustering criterion. Given that asymmetric competition is modeled parsimoniously and requires the estimation of a too small number of parameters this approach is less appropriate to estimate cross-promotion effects. 
The FEA model is the only one that allows for complete flexibility in the cross-competitive effects of the product categories' marketing variables (see, for example, Leeflang et al. 2000, p. 287). This model allows for unique parameters between and within all categories, at least in principle. However, it seems unrealistic to assume that in a market with many product categories, all cross-category effects are non-zero and unique. In addition, even with a modest number of product categories, the FEA model poses estimation problems. For example, if the number of product categories $J$ is 13 , we would have 494 parameters in the system of equations. An estimation sample of 1 year of daily observations (301) for 13 product categories contains 3,913 $(301 \times 13)$ observations. Thus, we must restrict the competitive structure. $^{2}$ To this end we calibrate the CCHM model.

This model has been developed to study asymmetric competition among many brands in a single product category. We apply it in a new setting and instead consider competition across product categories within a store, driven by supported and unsupported price promotions. Foekens et al. (1997) apply this model with different demand levels that account for interactions between the item and brand level. Campo et al. (2000) use this model to investigate the impact of location characteristics on the relative attractiveness of product categories within a store. However, they fail to consider the cross-category effects of price promotions.

We perform two analyses of two separate clusters of products: aperitifs and breakfast products. We assume no relations between these two clusters, because the purpose and timing of their consumption (in Spain at least) differs, and (almost) all categories of one cluster sell on a different floor than the categories of the other. The demand interdependencies within each cluster may be positive, negative, or zero. We determine potential non-zero cross-relations, in line with a specification of the CCHM model, and calibrate the model for each cluster.

To estimate the parameters of the CCHM model, we undertake three consecutive steps, each of which consists of several substeps (see Table 3). First, we estimate the parameters of an extended attraction (EA) model for each product category. Second, we identify cross-category effects by cross-correlating the residuals of a given product category with each marketing variable of every competitive product category within the same cluster of (12 or 13) categories. Therefore, we recognize potential cross-category effects on the basis of the statistical significance of the simple correlations $(p<$ 0.05). Third, to estimate the CCHM model, we add the

\footnotetext{
${ }^{2}$ The FEA model includes a constant term, 11 month dummies, and $13 \times 2$ (supported and unsupported) promotion effects for each category, which means $13 \times(1+11+26)=494$ parameters.
}

supported price (index) and unsupported price (index) of categories identified as potential sources of asymmetric competition for a given product category to the independent variables of the EA model. The resulting asymmetric CCHM model can formally be represented as:

$$
\begin{gathered}
R S_{i, t}=\frac{A_{t t_{i, t}}}{\sum_{j=1}^{J} A t t_{j, t}} \\
=\frac{\exp \left[C_{i}+\sum_{m=2}^{12} \lambda_{i m} \operatorname{Month}_{m, t}+\sum_{r \in\left(i, W_{i}\right)} \beta_{i r} S P I_{r, t}+\sum_{r \in\left(i, X_{i}\right)} \delta_{i r} N S P I_{r, t}\right]}{\sum_{j=1}^{J} \exp \left[C_{j}+\sum_{m=2}^{12} \lambda_{j m} \operatorname{Month}_{m, t}+\sum_{v \in\left(j, W_{j}\right)} \beta_{j v} S P I_{v, t}+\sum_{v \in\left(j, X_{j}\right)} \delta_{j v} \operatorname{NSPI}_{v, t}\right]}+u_{i, t},
\end{gathered}
$$

where $R S_{i, t}$ is the revenue share of product category $i$ at time $t ; A t t_{i, t}$ is the attraction of category $i$ at time $t ; j=1, \ldots$, $i, \ldots, J ; C_{i}$ is the intercept of category $i ;$ Month $_{m, t}$ is a monthly dummy variable that takes a value of 1 if period (day) $t$ belongs to month $m$ and 0 otherwise, with $m=2, \ldots$, 12; $S P I_{i, t}$ is a measure of the supported price (index) of category $i$ at time $t ; N S P I_{i, t}$ is a measure of the unsupported (non supported) price (index) of category $i$ at time $t$; and $W_{i}$ and $X_{i}$ represent subsets of categories with potential supported and unsupported cross-price (index) effects on the revenue share of product category $i$, respectively, obtained from the residual analyses (second stage), and $u_{i, t}$ is the disturbance term. If $r \neq i$, the parameters $\beta_{i r}$ and $\delta_{i r}$ represent the supported and unsupported cross-price (index) effects of category $r$ on $A t t_{i, t}$, respectively. If $r=i$, the parameters $\beta_{i i}$ and $\delta_{i i}$ represent the supported and unsupported own-price (index) effects on $A t t i$, , respectively. We include a monthly dummy variable to take into account the seasonal effects of some product categories. For example, in Spain, the heat of summer months prompts increased consumption of beer and declining consumption of red wine. We provide the measurement details of $R S_{i, t}, S P I_{i, t}$, and $N S P I_{i, t}$ in Appendix 1.

To estimate the parameters of Eq. 1, we use logcentering (Cooper and Nakanishi 1988). Because we use shares of categories that belong to the same cluster, we do not need to account for day-of-the-week effects and trends in sales. In turn, we do not apply a filtering technique (cf. Leeflang et al. 2008). If we apply ordinary least squares (OLS) to Eq. 1, the estimates are unbiased but not efficient (Foekens et al. 1997), because $u_{i, t}$ does not follow the usual assumptions required for OLS estimation. In general, $u_{i, t}$ is contemporaneously correlated with $u_{j, t}, j \neq i$, because we estimate Eq. 1 simultaneously for all categories $j=1, \ldots, J$, and it represents a system of $J$ seemingly unrelated regressions (SUR; cf. Zellner 1962). The SUR estimation procedure accounts for heteroscedasticity and contemporaneous correlation in 
Table 3

Estimation procedure to calibrate Eq. 1

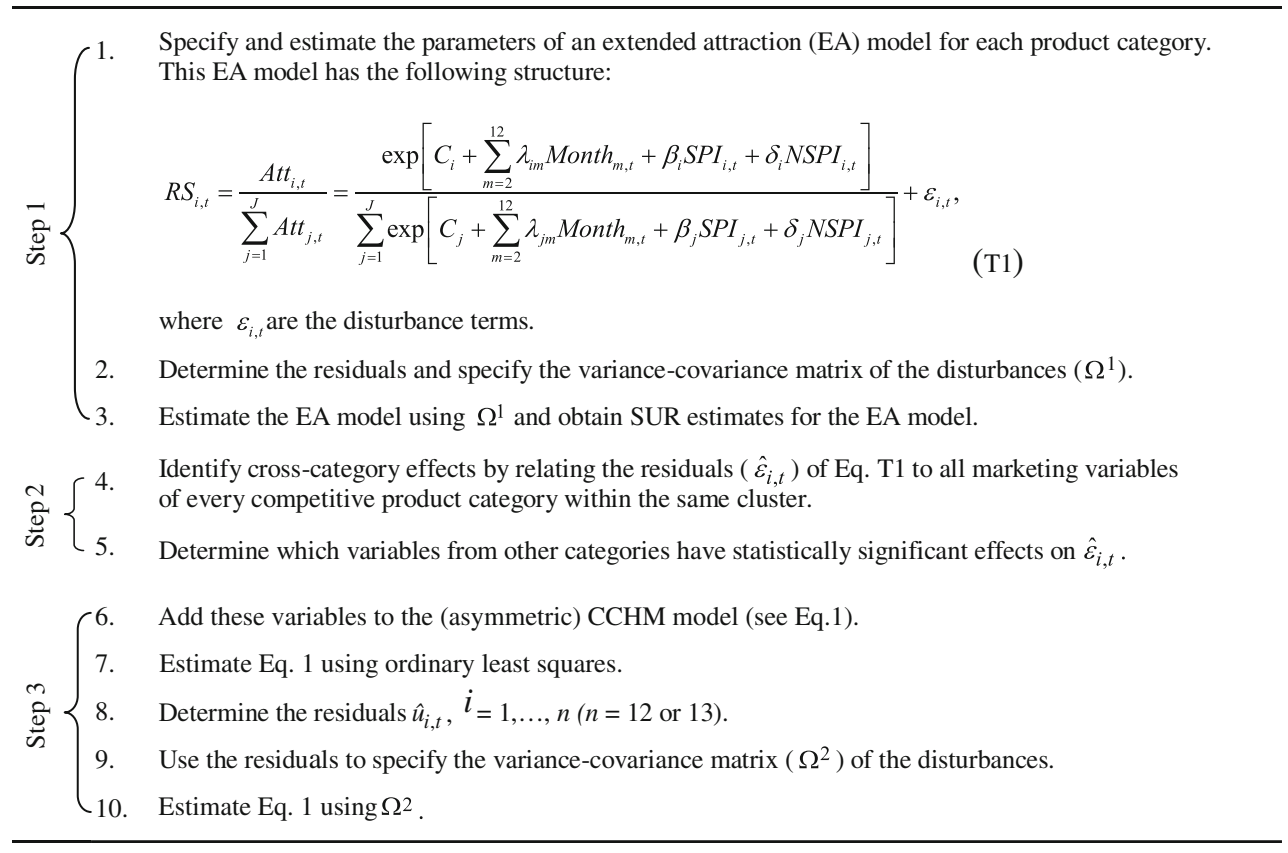

the errors across equations; it also yields unbiased and efficient parameter estimates.

As the expression for the corresponding cross-elasticities (ignoring the time subscript $t$ ) shows, the CCHM model accommodates asymmetric competition:

$$
\begin{aligned}
& S C P I R_{i c}=\left(\beta_{i c}-\sum_{s \in K_{c}} R S_{s} \beta_{s c}\right) S P I_{c}, \text { and } \\
& N S C P I R_{i c}=\left(\delta_{i c}-\sum_{s \in Q_{c}} R S_{s} \delta_{s c}\right) N S P I_{c} i \neq c,
\end{aligned}
$$

where $S C P I R_{i c}$ is the supported cross-price (index) elasticity of category $c$ on the revenue share of category $i$; $N S C P I R_{i c}$ is the unsupported (non supported) cross-price (index) elasticity of category $c$ on the revenue share of category $i$; and $K_{c}$ and $Q_{c}$ represent subsets of categories affected by the supported and unsupported price (index), respectively, of product category $c$. From Eq. 2 , if $i=c$, we can obtain the equivalent expression for $o w n$ elasticities: $S O P I R_{\mathrm{ic}}$ and $N S O P I R_{\mathrm{ic}}$ respectively.

In the first step, to estimate the parameters of the CCHM model, we estimate the parameters of the EA model using the SUR estimation procedures for both clusters (not shown here). Specifically, we delete one equation (category) of the system for each cluster (e.g., can of razorshells for aperitifs; sugar for the breakfast cluster), because the sum of the disturbances equals 0 for each $t$. The Durbin-Watson statistics and an analysis of all residuals indicate that several residual series follow autoregressive processes. Therefore, we follow Park's (1967) procedure to detect autocorrelation in SURs and use the Prais-Winsten transformation to remove autocorrelations (Greene 2003).

In the second step, we obtain 22 of the 484 possible significant correlations between the residuals from the EA model and the cross-promotional variables of the competing categories, which feature 13 in the aperitif cluster and 9 in the breakfast cluster. That is, we identify 22 potential cross-category effects. We do not expect interdependencies across all categories within a cluster, nor do we make any assumption about which cross-category effects we will find, because we expect interdependencies between unrelated (complementary and substitute) categories.

In the third step of our estimation procedure, we add variables with significant correlations to the CCHM model and then estimate the model using a SUR estimation procedure. The own- and cross-price (index) elasticities of this model appear in Table 4. The elasticities measure the impact of the supported and unsupported price index (SPI, NSPI) of items in the category on the category's revenue share. They also measure the impact of the supported and unsupported price index on the revenues of the category, because the revenues of the cluster (i.e., total category revenues) are 
not affected by the promotional activities. ${ }^{3}$ Our analysis of all series of residuals indicates no autocorrelation problems.

Explaining promotion elasticities: effects of moderators

We next attempt to explain own- and cross-category promotion elasticities through a second (-stage) analysis.

Own elasticities We find 14 (of 23) significant supported and 8 (of 23) unsupported own-price (index) elasticities. There are several possible explanations for the (absolute value of the) un/supported own price (index) (NSOPIR*/ $\left.S O P I R^{*}\right)^{4}$ elasticities across product categories, including discount frequency (supported $S D F_{i}$ or unsupported $N S D F_{i}$ ), discount depth (supported $S D D_{i}$ or unsupported $\left.N S D D_{i}\right)$, and competitive intensity $(C I)$. We derive

$$
\begin{aligned}
& \operatorname{SOPIR}_{i}^{*}=\varphi_{0}+\varphi_{1} S D F_{i}+\varphi_{2} S D D_{i}+\varphi_{3} C I_{i}+\varepsilon_{i}, \text { and } \\
& \text { NSOPIR }_{i}^{*}=\gamma_{0}+\gamma_{1} N S D F_{i}+\gamma_{2} N S D D_{i}+\gamma_{3} C I_{i}+\vartheta_{i},
\end{aligned}
$$

for all $i=1, \ldots, j, \ldots, J$, such that $\varphi_{d}$ and $\gamma_{d}$ for $d=0, . ., 3$ are parameters; and $\varepsilon_{i}$ and $\vartheta_{i}$ are disturbance terms. We provide the measurement details of these variables in Appendix 2.

The models in this second (-stage) analysis incorporate heteroscedastic errors (Wittink 1977), so we use a generalized least squares estimation procedure to account for heteroscedastic errors (Greene 2003).

Cross-category elasticities Because we find a limited number of significant cross-elasticities, we consider supported and unsupported promotion elasticities simultaneously.

We introduce and use a binary dependent variable that uses two values ( 0 and 1; a dummy) to distinguish between significant and insignificant cross-price (index) elasticities, $D C P I R_{i c}{ }^{5}$ We specify a logit model to explain crosspromotion elasticities. In this case, we use the distance between two categories $i$ and $c\left(D C_{i c}\right)$ and two dummy variables as predictor variables. The first dummy variable distinguishes supported from unsupported cross-price (index) elasticities $\left(D C F_{i c}\right)$, whereas the second distinguishes

\footnotetext{
$\overline{3}$ These analyses are available on request.

${ }^{4}$ Given that we now consider absolute values we add an *-sign to the variables.

${ }^{5}$ We also use as a dependent variable the absolute value of significant and insignificant cross-price (index) elasticities. However, the results do not improve. Therefore, the magnitude of cross-elasticities does not depend on the distances between categories, but the probability of interdependencies between categories depends on these distances.
}

between cross-elasticities in product categories located on the ground floor and those on the first floor $\left(D F L_{i c}\right)$. Thus,

$$
\begin{aligned}
D_{C P I R}= & \rho_{0}+\rho_{1} D C_{i c}+\rho_{2} D C F_{i c}+\rho_{3} D F L_{i c}+\omega_{i c}, \\
& \text { for all } j=1 \ldots, i \ldots, c, \ldots, J ; i \neq c
\end{aligned}
$$

where

$D_{C P I R} i c= \begin{cases}1 & \text { if } S C P I R_{i c} \neq 0 \text { or NSCPIR } \\ i c & \neq 0 \\ 0 & \text { otherwise. }\end{cases}$

In addition, $\rho_{l}$ for $l=0, \ldots, 3$ are parameters, and $\omega_{i c}$ is a disturbance term. We provide the measurement details of these variables in Appendix 2.

\section{Empirical results}

Category attraction model (Eq. 1)

We provide the estimation results in Table 4.

Own effects The results from the CCHM model (Table 4) demonstrate that in $46 \%$ of cases, price promotions expand own-category revenues. This confirms P1a. In one case $(2 \%)$, the price promotions reduce own revenues, and in $52 \%$ of cases, they have no effect. These results show some correspondence with the findings presented by Nijs et al. ( 2001 ; i.e., $58 \%, 5 \%$, and $37 \%$, respectively). In contrast to the significant promotional effects, the unsupported price promotions of enriched milk reduce its own revenues, likely because of the frequent use of unsupported price promotions for lower priced items, which cause consumers to substitute for higher priced items.

Cross-category effects As we also reveal in Table 4, the significant asymmetric demand interdependencies, both positive and negative, are similar to Duvvuri et al.'s (2007), Leeflang et al.'s (2008), Manchanda et al.'s (1999), and Walters's (1991) findings regarding cross-category effects. We find 18 significant cross-promotional effects, 9 in each cluster, or $4 \%$ of all possible pairs (consistent with the $5 \%$ indicated by Hruschka et al. 1999). The probability that a price promotion in a category affects the sales of at least one other category is 0.61 (14 out of 23). The number of categories affected is low ( 1 or 2 of 10 or 11 potential categories per cluster), which confirms P1b. The limited number of cross-promotional effects in prior studies that consider far fewer categories therefore is not due to the small number of categories. We also find that $39 \%$ of significant 
Table 4 Own- and cross-price (index) elasticities

\begin{tabular}{|c|c|c|c|c|c|}
\hline \multirow[t]{2}{*}{ Category Promoted } & \multicolumn{2}{|c|}{ Own-Elasticities } & \multirow[t]{2}{*}{ Category Affected } & \multicolumn{2}{|c|}{ Cross-Elasticities } \\
\hline & SPI & NSPI & & SPI & NSPI \\
\hline \multicolumn{6}{|c|}{ Aperitif Cluster } \\
\hline Beer 11 & n.s. & n.s. & - & & \\
\hline \multirow[t]{2}{*}{ Beer33cl } & $-0.88(0.16)$ & $-1.15(0.38)$ & Mussels & $-0.18(0.15)$ & \\
\hline & & & Red wine & $-0.27(0.28)$ & \\
\hline Mussels & $-0.48(0.13)$ & n.s. & Beer $33 \mathrm{cl}$ & & $-0.22(0.12)$ \\
\hline Cockles & n.s. & n.s. & - & & \\
\hline Clams & $-1.31(0.40)$ & $-1.02(0.48)$ & - & & \\
\hline Tuna & n.s. & n.s. & Clams & $-0.72(0.38)$ & $1.05(0.48)$ \\
\hline Asparagus & $-0.91(0.15)$ & n.s. & Beer 11 & & $0.77(0.31)$ \\
\hline Red wine & n.s. & $-0.99(0.45)$ & Olives & $-1.39(0.35)$ & \\
\hline White/rose wine & $-0.82(0.36)$ & $-2.62(0.66)$ & - & & \\
\hline Potato chips & $-0.25(0.15)$ & n.s. & Tuna & $-0.29(0.12)$ & \\
\hline Olives & $-0.48(0.22)$ & n.s. & Mussels & $-0.50(0.22)$ & \\
\hline \multicolumn{6}{|c|}{ Breakfast Cluster } \\
\hline Juice mini & n.s. & n.s. & - & & \\
\hline Juice 11 & $-0.48(0.20)$ & n.s. & Soluble cocoa & $-0.47(0.26)$ & \\
\hline Standard cookies & $-0.45(0.12)$ & n.s. & - & & \\
\hline Filled cookies & $-0.44(0.19)$ & n.s. & - & & \\
\hline Soluble cocoa & $-0.80(0.33)$ & n.s. & - & & \\
\hline Soluble coffee & $-8.07(1.02)$ & n.s. & Normal coffee & & $3.74(0.98)$ \\
\hline \multirow[t]{2}{*}{ Normal coffee } & n.s. & $-1.01(0.29)$ & Soluble cocoa & $0.57(0.25)$ & \\
\hline & & & Skimmed milk & & $1.31(0.31)$ \\
\hline \multirow[t]{2}{*}{ Unskimmed milk } & n.s. & $-0.31(0.19)$ & Normal coffee & $-0.43(0.15)$ & \\
\hline & & & Skimmed milk & & $-0.28(0.15)$ \\
\hline Skimmed milk & n.s. & n.s. & Semi-skimmed milk & $0.42(0.13)$ & \\
\hline Semi-skimmed milk & $-0.96(0.03)$ & $-1.00(0.39)$ & - & & \\
\hline Enriched milk & n.s. & $0.14(0.07)$ & Semi-skimmed milk & $0.56(0.18)$ & \\
\hline Cereal & $-0.53(0.04)$ & n.s. & Standard cookies & $-0.61(0.23)$ & \\
\hline
\end{tabular}

Standard errors are in parentheses. SPI = (feature-) supported price (index), NSPI = unsupported price (index). n.s. $=$ not significant

cross-promotional effects are negative (positive price elasticities) and $61 \%$ are positive (negative price elasticities), which indicate substitutes and complementarities, respectively. The finding of more complementaries than substitutes corresponds with Leeflang et al.'s (2008) results.

In the aperitif cluster, for example, the revenues of mussels increase in response to supported price promotions of beer and olives. ${ }^{6}$ Negative cross-promotional effects also emerge; for example, the unsupported price promotions of asparagus diminish the revenues of beer. Even though the mussels category shares several brand names with the

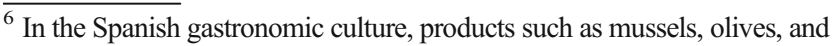
beer are complementary products, often consumed together as aperitifs.
}

cockles category, unlike Erdem and Sun (2002), we do not find interdependencies between them.

We instead find interdependencies between categories that are not traditionally perceived as complementaries or substitutes, such as the effect of (supported and unsupported) price promotions of tuna on the revenues of clams or the previously noted effect of unsupported price promotions of asparagus on the revenues of beer. Campo et al. (2000) find similar types of cross-category effects; they may result from the proximity of the product categories in the store. Interdependencies in the breakfast cluster similarly may be due to proximity; $11 \%$ of the significant cross-promotional elasticities in this cluster occur between categories located closest to each other (e.g., normal coffee with skim milk, 
Table 5 Parameter estimates of promotional intensity and category characteristic effects on own promotional elasticities

$$
\begin{aligned}
& S_{S P I R}^{*}=-1.47+0.01 \times S D F_{i}+2.70^{\mathrm{c})} \times S D D_{i}+0.10 \times C I_{i} \\
& \text { (0.91) }(0.02) \quad(1.42) \quad(0.06) \\
& N_{S O P I R}^{*}=-0.73+0.0002 \times N S D F_{i}-0.52 \times N S D D_{i}+0.03 \times C I_{i} \\
& \begin{array}{lll}
(0.47)(0.004) \quad(4.54) & (0.03)
\end{array} \\
& \text { R-squared }=0.23
\end{aligned}
$$

where:

$(N) S O P I R_{i}^{*}=$ the absolute value of the own (un-) supported price (index) elasticity of category $i$,

$(N) S D F_{i}=$ the (un-) supported discount frequency of category $i$, $(N) S D D_{i}=$ the (un-) supported discount depth of category $i$,

$C I_{i}=$ competitive intensity of category $i$.

Standard errors are in parentheses

${ }^{\mathrm{a}} p<0.01$

${ }^{\mathrm{b}} p<0.05$

${ }^{\mathrm{c}} p<0.10$

enriched milk with semi-skim milk), and $83 \%$ are between categories whose distance is less than the average distance across categories in the cluster. Only 6\% occur between categories at great distances apart (e.g., red wine and olives). This finding corresponds to P5; we also test P5 more formally in a subsequent analysis.

Comparing the own- and cross-category elasticities, we find that in general and in absolute value, the significant own-category elasticities are greater than the significant cross-category elasticities (1.11 and 0.85 , respectively), in support of P2.

In both categories, the percentage of significant own supported price promotion effects ( 7 out of 11/12) is greater than that of own unsupported price promotion effects ( 4 out of 11/12), in line with Van Heerde et al. (2001, 2004), which confirms P3a. We also discover more significant supported price cross-elasticities than unsupported ones $(\mathrm{P} 3 \mathrm{~b})$.

Explaining promotion elasticities: effects of moderators (Eqs. 3 and 4)

Own elasticities Table 5 shows that there is no evidence to confirm that the magnitude of non-supported own-price (index) elasticities is affected by the depth of the discounts, nor do we find evidence that discount frequency, influence the own-price (index) elasticities, whether supported or not. However, the deep discounts lead to supported own-price (index) elasticities that are greater (in absolute value) $\left(\hat{\varphi}_{2}=2.70 ; p=0.09\right)$, which suggests that deep discounts induce non-loyal consumers to switch categories and loyal consumers to engage in heavier stockpiling and consumption behaviors (Ailawadi et al. 2006; Krishna 1994; Raju 1992; Walters and Bommer 1996). At the 11\% level we find evidence that competitive intensity has a significant effect on the absolute value of the own price elasticities (P4).

Cross-category elasticities As Table 6 shows, the probability of interdependencies between pairs of categories increases when the spatial distance between them decreases,

Table 6 Parameter estimates of distance effects on cross-promotional elasticities

$$
\begin{gathered}
D C P I R_{i c}=-2.87^{*}-0.02^{* * *} \times D C_{i c}+0.23 \times D C F_{i c}+0.16 \times D F L_{i c} \\
(0.45) \quad(0.01) \\
\text { McFadden R-squared }=0.11
\end{gathered}
$$

$\begin{aligned} & \text { where: } \\ & D C P I R_{i c}\end{aligned}= \begin{cases}1 & \text { if } S C P I R_{i c} \neq 0 \text { or } N S C P I R_{i c} \neq 0 \\ 0 & \text { otherwise, }\end{cases}$

$S C P I R_{i c}=$ the supported cross-price (index) elasticity of category $c$ on the revenue share of category $i$,

$N S C P I R_{i c}=$ the unsupported cross-price (index) elasticity of category $c$ on the revenue share of category $i$,

$D C_{i c}=$ the spatial distance between product categories $i$ and $c$ (note that $D C_{i c} \equiv D C_{c i}$ ),

$D C F_{i c}=$ dummy variable that takes a value 1 if the cross-price (index) elasticity of category $c$ on category $i$ is feature supported and 0 if it is unsupported,

$D F L_{i c}= \begin{cases}1 & \text { if categories } i \text { and } c \text { are located on the ground floor of the store } \\ 0 & \text { otherwise. }\end{cases}$

Standard errors are in parentheses

$* p<0.01$

$* * p<0.05$

$* * * p<0.10$ 
in support of P5. However, this evidence is moderate $\left(\hat{\rho}_{1}=-0.02 ; p=0.08\right)$ and reflects the modest number of significant cross-category effects. The results provide no evidence that the probability of interdependencies between pairs of categories depends on the floor on which they are sold or whether discounts receive promotional support (Table 7).

\section{Conclusions}

Retailers may benefit from cross-category promotion effects if the cross-category complementary effects are greater than the cross-category substitution effects. Extant studies consider interdependencies among a limited number of related product categories at the item demand level and use weekly data. We instead develop a framework for the impact of price promotions and features on category performance, in which we consider interdependencies among a substantial number of related and less related categories at the category demand level. With this model, an individual store can estimate store-specific effects using daily data. To explain category revenue share, we rely on the asymmetric multiplicative competitive interaction structure developed by Carpenter et al. (1988) to model a substantial number of cross-category effects (CCHM model) and account for both positive and negative crosscategory effects. Positive cross-category effects are common among complementary goods, but they also may exist when the same brand name appears on items that belong to multiple categories (i.e., umbrella branding, Erdem and Sun 2002) or if an attractively priced item represents part of a set that tends to be purchased together (e.g., loss leaders, Mulhern and Leone 1991). Negative cross-category effects, in contrast, imply substitution.

Because of the difficulties of accommodating crosscategory effects for many categories at the same time, we apply the CCHM model to two clusters (aperitifs and breakfast products) independently. The CCHM model employs an empirical stepwise approach to determine relevant instruments with cross-effects.

Overall, $46 \%$ of price promotions, both supported and unsupported, expand own-category revenues (or revenue share), $2 \%$ reduce own revenues, and $52 \%$ have no effect. These percentages imply that more than half of all price promotions lead to substitution effects between items/brands within a category, without contributing to the revenues of the promoted categories. The supported price (index) has a greater impact on own revenues than does the unsupported price (index). On average, a decrease (in the short term) of $10 \%$ in the supported price (index) increases (daily) own revenues by $12 \%$, whereas a $10 \%$ decrease in the unsupported price (index) leads to an increase of $10.30 \%$ of (daily) own revenues. These magnitudes also are in line with Nijs et al. (2001). However, the magnitude of own-price (index) elasticity varies across product categories, such that the effectiveness of supported price promotions for increasing category revenues is greater in categories with deeper supported discounts and when there are more competitors within the category. This result confirms findings from previous studies (Krishna 1994; Raju 1992). We find no evidence that categories with deeper unsupported discounts have higher unsupported own-price (index) elasticities. Nor do we find evidence that the frequency of discounts affects the magnitude of own-price (index) elasticities, whether supported or unsupported.

A promotional price change in a category has, on average, a $61 \%$ probability of affecting the revenues (or revenue share) of at least one other category. The number of categories affected by the price promotion of a focal category is one or two. In our study, $61 \%$ of the crossprice (index) effects are negative (complementary), and $39 \%$ are positive (substitution). The substitution elasticities tend to be greater than the complementary elasticities that measure effects ( 1.20 and -0.49 , respectively).

The probability of interdependencies between categories increases if they are located near each other, though our evidence is moderate $(p=0.08)$. This finding corresponds with Campo et al.'s (2000) and Heilman et al.'s (2002) results.

\section{Managerial implications}

Price promotions generally lead to short-term sales increases; there is significant doubt, however, about whether increases lead to more profit for retailers and/or manufacturers. We investigate whether promotions benefit revenues through cross-promotional effects and find that half of the promotions lead to substitution effects between items/brands within a category, without increasing the revenues of the categories. That is, many (price) promotions lead to substitution effects between items/brands within a category. The number of categories affected by a promotion is limited. Furthermore, cross-promotional effects lead to not only more revenues in complementary categories but also substitution effects, perhaps due to the budget restrictions consumers experience when they shop. The argument widely used by manufacturers when they ask for promotional allowances by pinpointing crosspromotional effects thus has not much real value. Retailers that allow manufacturer-dominated promotions can create cross-promotional benefits only if these promotions are supported and when the other categories that may be affected are located close by in the store. These boundary conditions demand a better understanding by store and category managers about the customer-based relations between categories. In addition, manufacturers that supply 
Table 7 Overview of expectations

\begin{tabular}{ll} 
Expectations & Support ? \\
\hline P1: & The promotional effects of SKUs/brands in category $i$ (a) primarily affect revenues in category $i$, \\
& and (b) influence the revenues of only a limited number of other categories (i.e., cross-promotional effects). \\
P2: & Significant own-category elasticities are larger than cross-category elasticities (in absolute values). \\
P3: & Effect of a promotion: (a) within (b) between categories is affected by the support of a promotion. \\
P4: & The number of brands in a category has a negative impact on own price elasticities. \\
P5: & Cross-promotion elasticities are larger (in absolute value) if the distance between the categories is smaller.
\end{tabular}

items/brands in different categories to channel members should recognize that cross-promotional effects are very limited.

\section{Directions for further research}

The ongoing focus on cross-category effects has great theoretical and substantive importance. Scholars interested in understanding consumer behavior therefore should continue to explore the purchase and consumption characteristics that explain category dependencies.

This study pertains to clusters of product categories in a Spanish hypermarket. Hence we realize that our findings are just a new "data point" that gives insights into the effects of cross-promotions. Although the model we develop can be applied fruitfully in other, similar contexts, we cannot generalize our specific findings. Researchers therefore are readily invited to apply our methodology to other combinations of product categories in other stores. We applied the CCHM model to account for asymmetries in competition between categories which is also a limitation. A more flexible model that requires many more observations to estimate a high number of parameter such as the FEA model may be more appropriate. Another model that accounts for asymmetric competition, the CAA model, which has much less parameters and which is more difficult to estimate might be another option to find crosspromotional effects between categories.

In this study we studied cross-category effects for a retailer (at the store level). Manufacturers such as Phillips, Procter \& Gamble and Unilever that sell products in multiple product categories could also benefit from a better understanding of these cross-category effects. This points to another future research opportunity.

Marketing research devotes much attention to shortand long-term effects of price promotions and has revealed generally that their long-term effects are limited for retailers and manufacturers (Nijs et al. 2001). We further demonstrate that cross-promotional effects are limited, even if we consider a substantial number of categories. However, not many studies consider the effects of non-price promotions, and we lack sufficient knowledge of their effects. Academics therefore should direct their attention to the effects of non-price promotions to formulate answers to questions about whether these promotions lead to higher revenues in the same and other categories and to what degree.

Open Access This article is distributed under the terms of the Creative Commons Attribution Noncommercial License which permits any noncommercial use, distribution, and reproduction in any medium, provided the original author(s) and source are credited.

\section{Appendix 1}

Variable operationalization of category attraction model

\section{Revenue share of product category}

We use the revenue share of a product category as a criterion variable to compare the sales (units) of many different categories measured in incomparable units (kilograms, cans, etc.). First, we create a currency measure of item revenues in period $t$ by multiplying daily unit sales of an item $s$ that belongs to category $i$ with the average price for this item across the sample. We use the average price (item-specific constant) to maintain the desirable property that demand varies only in terms of unit sales and multiply unit sales by a constant that has only a scaling effect. Second, we calculate the category revenues in $t$ by aggregating the item revenues of the items that belong to category $i$. Third, we calculate the revenue share of each product category $\left(R S_{i, t}\right)$ by dividing the revenues of the category by the sum of the revenues of all product categories that belong to the same cluster. 


\section{Supported and unsupported price (index)}

In our data at the item level, we cannot distinguish promotional prices from regular prices and instead calculate price indices relative to the maximum price, ${ }^{7}$ following Foekens et al. (1999), Nijs et al. (2007), and Raju (1992). We estimate separate effects for two price index variables, based on supported and unsupported prices. Unsupported prices (index) are those not supported by featuring activities for the item with the discount in the same period. We calculate the minimum value of the supported price (index) across all items $s$ in category $i$ at time $t(s=1, \ldots, S(i))$, and define this value as the category-supported price (index) measure $\left(S P I_{i t}\right)$. We use a similar method to obtain the unsupported price (index) measure of category $i$ at time $t\left(N S P I_{i t}\right)$. Therefore:

$$
\begin{aligned}
& S P I_{i t}=\operatorname{Min}\left(S P I_{i 1, t}, \ldots, S P I_{i s, t}, \ldots, S P I_{i S(i), t}\right), \text { and } \\
& N S P I_{i t}=\operatorname{Min}\left(N S P I_{i 1, t}, \ldots, N S P I_{i s, t}, \ldots, N S P I_{i S(i), t}\right),
\end{aligned}
$$

where:

$$
\begin{aligned}
& S P I_{i s, t}=\left\{\begin{array}{l}
P I_{i s, t} \text { if } F E A T_{i s, t}=1 \\
0 \text { otherwise, }
\end{array}\right. \\
& N S P I_{i s, t}=\left\{\begin{array}{l}
P I_{i s, t} \text { if } F E A T_{i s, t}=0 \\
0 \text { otherwise }
\end{array}\right. \\
& P I_{i s, t}=\frac{P_{i s, t}}{P_{i s}^{\max }}, \\
& P_{i s}^{\max }=\operatorname{Max}\left(P_{i s, 1}, \ldots, P_{i s, T}\right),
\end{aligned}
$$

and

$F E A T_{i s, t}=$ dummy variable that takes the value of 1 if item $s$, which belongs to product category $i$, is featured at time $t$, and 0 otherwise.

We also define other (un-)supported price (index) measures of the category, such as the (market share) weighted and unweighted average of the (un-)supported price (index) across all items in a category. We applied the algorithm by Van Heerde (1999) that runs through daily actual price observations and determines which prices are regular and which are promotional. However, using these or other (un-)supported price (index) measures of the category does not improve the models' validity.

\footnotetext{
${ }^{7}$ The maximum price of each item across the year excludes outliers.
}

\section{Appendix 2}

Variable operationalization of promotion elasticities models

\section{Discount frequency}

The supported discount frequency at the item level consists of the number of days that each item is discounted with feature support in excess of $5 \%$. The supported discount frequency at the category level equals the market share weighted average of the item-supported discount frequencies. We obtain the unsupported discount frequencies using similar methods.

\section{Discount depth}

We measure the magnitude of the supported/unsupported discount offered by an item as the difference between the maximum price in that year (regular price) and the actual price on that day. By averaging the magnitude of (un-)supported discounts, we obtain a measure of (un-) supported price promotion depth. Furthermore, by computing a market share weighted average of the (un-)supported discounts offered on the items in the product category, we realize the category (un-)supported price promotion depth.

Our discount frequency and discount depth measures are conceptually similar to those adopted by Foekens et al. (1999), Nijs et al. (2001, 2007), and Raju (1992).

\section{Competitive intensity}

Our measure of competitive intensity involves the number of items in a category and is conceptually similar to that adopted by Narasimhan et al. (1996), Nijs et al. (2001, 2007), and Raju (1992).

\section{Distance between categories}

We measure the literal distance between categories in meters.

\section{References}

Ailawadi, K. L., Harlam, B. A., César, J., \& Trounce, D. (2006). Promotion profitability for a retailer: the role of promotion, brand, category, and store characteristics. Journal of Marketing Research, 43, 518-535.

Ailawadi, K. L., Harlam, B. A., César, J., \& Trounce, D. (2007). Practice prize report-quantifying and improving promotion effectiveness at CVS. Marketing Science, 26, 556-575.

Ailawadi, K. L., Beauchamp, J. P., Donthu, N., Gauri, D. K., \& Shankar, V. (2009). Communication and promotion decisions in 
retailing: a review and directions for future research. Journal of Retailing, 85(1), 42-55.

Bezawada, R., Balachander, S., Kannan, P. K., \& Shankar, V. (2009). Cross-category effects of aisle and display placements: a spatial modeling approach and insights. Journal of Marketing, 73(3), 99-117.

Campo, K., Gijsbrechts, E., Goossens, T., \& Verhetsel, A. (2000). The impact of location factors on the attractiveness and optimal space share of product categories. International Journal of Research in Marketing, 17, 255-279.

Carpenter, G. S., Cooper, L. G., Hanssens, D. M., \& Midgley, D. F. (1988). Modeling asymmetric competition. Marketing Science, 7, 393-412.

Cooper, L. G., \& Nakanishi, M. (1988). Market-share analysis: Evaluating competitive marketing effectiveness. Boston: Kluwer Academic Publishers.

Duvvuri, S. D., Ansari, A., \& Gupta, S. (2007). Consumers' price sensitivities across complementary categories. Management Science, 53, 1933-1945.

Erdem, T., \& Sun, B. (2002). An empirical investigation of the spillover effects of advertising and sales promotions in umbrella branding. Journal of Marketing Research, 39, 408-420.

Foekens, E. W., Leeflang, P. S. H., \& Wittink, D. R. (1997). Hierarchical versus other market share models for markets with many items. International Journal of Research in Marketing, 14, 359-378.

Foekens, E. W., Leeflang, P. S. H., \& Wittink, D. R. (1999). Varying parameter models to accommodate dynamic promotion effects. Journal of Econometrics, 89, 249-268.

Greene, W. H. (2003). Econometric analysis (5th ed.). New York: Macmillan.

Grewal, D., \& Levy, M. (2007). Retailing research: past, present, and future. Journal of Retailing, 83, 447-464.

Heilman, C. M., Nakamoto, K., \& Rao, A. G. (2002). Pleasant surprises: consumer response to unexpected in-store coupons. Journal of Marketing Research, 39, 242-252.

Helsen, K., \& Schmittlein, D. C. (1992). Some characterizations of stockpiling behavior under uncertainty. Marketing Letters, 3, 5-16.

Helson, H. (1964). Adaptation-level theory. New York: Cambridge University Press.

Hruschka, H., Lukanowicz, M., \& Buchta, C. (1999). Cross-category sales promotion effects. Journal of Retailing and Consumer Services, 6, 99-105.

Kamakura, W. A., \& Kang, W. (2007). Chain-wide and store-level analysis for cross-category management. Journal of Retailing, $83,159-170$

Krishna, A. (1994). The effect of deal knowledge on consumer purchase behavior. Journal of Marketing Research, 31, 76-91.

Krishna, A., Currim, I. S., \& Shoemaker, R. W. (1991). Consumer perceptions of promotional activity. Journal of Marketing, 55(2), 4-16.

Kumar, V., \& Pereira, A. (1995). Explaining the variation in shortterm sales response to retail price promotion. Journal of the Academy of Marketing Science, 23(3), 155-169.

Leeflang, P. S. H., Wittink, D. R., Wedel, M., \& Naert, Ph A. (2000). Building models for marketing decisions. Boston: Kluwer Academic Publishers.

Leeflang, P. S. H., Parreño-Selva, J., van Dijk, A., \& Wittink, D. R. (2008). Decomposing the sales promotion bump accounting for cross-category effects. International Journal of Research in Marketing, 25(3), 201-214.

Manchanda, P., Ansari, A., \& Gupta, S. (1999). The "shopping basket": a model for multicategory purchase incidence decisions. Marketing Science, 18(2), 94-114.

Mela, C. F., Gupta, S., \& Lehmann, D. R. (1997). The long-term impact of promotions and advertising on consumer brand choice. Journal of Marketing Research, 34, 248-261.
Mulhern, F. J., \& Leone, R. P. (1991). Implicit price bundling of retail products: a multiproduct approach to maximizing store profitability. Journal of Marketing, 55(4), 63-76.

Narasimhan, C., Neslin, S. A., \& Sen, S. K. (1996). Promotional elasticities and category characteristics. Journal of Marketing, 60 (2), 17-30

Nijs, V. R., Dekimpe, M. G., Steenkamp, J.-B., \& Hanssens, D. (2001). The category-demand effects of price promotions. Marketing Science, 20, 1-22.

Nijs, V. R., Srinivasan, S., \& Pauwels, K. (2007). Retail-price drivers and retailer profits. Marketing Science, 26, 473-487.

Park, R. W. (1967). Efficient estimation of a system of regression equations when disturbances are both serially and contemporaneously correlated. Journal of the American Statistical Association, 62, 500-509.

Parreño-Selva, J., Leeflang, P. S. H., \& Van Doorn, J. (2009). Efecto de las promociones del precio sobre la venta de productos no promocionados: papel moderador del tipo de visita del cliente. Revista Española de Investigación de Marketing ESIC, 13(2), 73-90.

Raju, J. S. (1992). The effect of price promotions on variability in product category sales. Marketing Science, 11, 207-220.

Ratchford, B. T. (1980). The value of information for selected appliances. Journal of Marketing Research, 17, 14-25.

Seetharaman, P. B., Chib, S., Ainslie, A., Boatwright, P., Chan, T., Gupta, S., et al. (2005). Models of multi-category choice behavior. Marketing Letters, 16, 239-254.

Song, I., \& Chintagunta, P. K. (2006). Measuring cross-category price effects with aggregate store data. Management Science, 52, 1594-1609.

Song, I., \& Chintagunta, P. K. (2007). A discrete-continuous model for multicategory purchase behavioral households. Journal of Marketing Research, 44, 595-612.

Srinivasan, S., Pauwels, K., Hanssens, D., \& Dekimpe, M. G. (2004). Do promotions benefit manufacturers, retailers, or both? Management Science, 50, 617-629.

Vanden Abeele, P., Gijsbrechts, E., \& Vanhuele, M. (1990). Specification and empirical evaluation of a cluster-asymmetry market share model. International Journal of Research in Marketing, 7, 223-247.

Van Heerde, H. J. (1999). Models for sales promotion effects based on store-level scanner data. Capelle a/d IJssel: Labyrint Publication.

Van Heerde, H. J., Leeflang, P. S. H., \& Wittink, D. R. (2001). Semiparametric analysis to estimate the deal effect curve. Journal of Marketing Research, 38, 197-215.

Van Heerde, H. J., Leeflang, P. S. H., \& Wittink, D. R. (2004). Decomposing the sales promotion bump with store data. Marketing Science, 23, 317-334.

Walters, R. G. (1991). Assessing the impact of retail price promotions Journal of Marketing, 55(2), 17-28.

Walters, R. G., \& Bommer, W. (1996). Measuring the impact of product and promotion-related factors on product category price elasticities. Journal of Business Research, 36, 203-216.

Walters, R. G., \& Mackenzie, S. (1988). A structural equations analysis of the impact of price promotions on store performance. Journal of Marketing Research, 25, 51-63.

Wedel, M., \& Zhang, J. (2004). Analyzing brand competition across categories. Journal of Marketing Research, 41, 448-456.

Wittink, D. R. (1977). Exploring territorial differences in the relationship between marketing variables. Journal of Marketing Research, 14, 145-155.

Wittink, D. R., Addona, M. J., Hawkens, W. J. \& Porter, J. C. (1988). SCAN*PRO: The estimation, validation and use of promotional effects based on scanner data. Internal paper, Cornell University.

Zellner, A. (1962). An efficient method for estimating seemingly unrelated regressions and tests for aggregate bias. Journal of the American Statistical Association, 58, 977-992. 